\title{
Influence of dietary myoinositol on nerve conduction and inositol phospholipids in normal and diabetic rats
}

\author{
J . G . R. J E F F E R Y S, K. P. P A L M A N O, A. K . S H A R M , A N D \\ P. K. T H O M A S
}

From the Department of Neurological Science, Royal Free Hospital School of Medicine, London, and Department of Biochemistry, University Hospital and Medical School, Nottingham

SUMMARY Observations have been made on motor conduction velocity in the tibial nerve of rats given $35 \%$ myoinositol in the diet. Comparison between the values before and with up to nine weeks of dosing revealed no alteration in conduction velocity. In such animals, the free myoinositol content in the sciatic nerve was increased; there was no detectable alteration in the lipid inositol concentration. In a second series of experiments, tibial motor nerve conduction velocity in rats with streptozotocin-induced diabetes was compared with conduction velocity in diabetic animals given $1 \%$ supplementary dietary myoinositol, and with a control group of nondiabetic rats. Conduction velocity was reduced in the diabetic animals, but no influence from the added dietary myoinositol was detected. No statistically significant difference in sciatic nerve myoinositol was demonstrated, but the sorbitol and fructose concentrations were increased. Those animals fed the myoinositol supplement had a significantly lower lipid inositol content. The significance of these findings is discussed.

Myoinositol, a cyclic hexitol, is a precursor of polyphosphoinositides. These are present in plasma membranes, including those of neurones (Eichberg and Hauser, 1973). They show a rapid turnover rate in nerve trunks (Yagihara et al., 1969; White and Larrabee, 1973), and this has led to the proposal that they may be involved in neural transmission (Kai and Hawthorne, 1969). Di- and triphosphoinositides are present and both exhibit $\mathrm{Ca}^{2+}+$ ion-binding properties. It has been postulated that by interconversions between different inositol lipids, the quantity of $\mathrm{Ca}^{2+}$ ions bound at specific sites in the plasma membrane might be altered and that this could be involved in the generation and propagation of action potentials. Kai and Hawthorne (1969) and Hawthorne and Kai (1970) originally proposed that $\mathrm{Ca}^{2}$ ions bound to pairs of di- or triphosphoinositide molecules might obstruct ion channels through the plasma membrane. Phosphatidylinositol has a lower affinity for $\mathrm{Ca}^{2+}$

Address for correspondence and reprint requests: Professor P. K. Thomas, Royal Free Hospital, Pond Street, London NW3 2QG, England.

Accepted 31 October 1977 ions and dephosphorylation to this form might release $\mathrm{Ca}^{2+}$ and open the channels. Hendrickson and Reinertsen (1971) postulated a slightly different mechanism. They (Hendrickson and Reinertsen, 1969) had concluded that triphosphoinositides possess a greater affinity for $\mathrm{Ca}^{2}+$ than diphosphoinositides and, therefore, suggested that interconversion between these two polyphosphoinositides might be sufficient to control the opening and closure of axolemmal ion channels.

The role of myoinositol in nerve conduction remains speculative, but a number of recent reports have implicated myoinositol in alterations in peripheral nerve function. Clements et al. (1973) and De Jesus et al. (1974) found that rats fed a diet containing $35 \%$ myoinositol developed reduced nerve conduction velocity. Myoinositol is retained during renal failure, and these authors, therefore, suggested that hypermyoinositolaemia may be responsible for the development of uraemic polyneuropathy. Reznek et al. (1977) reported that in patients with chronic renal failure, the plasma myoinositol level showed a significant negative correlation with sural nerve conduction velocity, 
although no correlation with the occurrence of clinical neuropathy was detected. They concluded that, although hypermyoinositolaemia may lead to reduced nerve conduction velocity, there was no evidence that it was related to the development of symptomatic peripheral neuropathy.

Conversely, it has been suggested that reduced peripheral nerve myoinositol concentrations may be related to reduced nerve conduction velocity in diabetes. In alloxan- and streptozotocin-induced diabetes in the rat, nerve conduction velocity is reduced (Eliasson, 1964; Preston, 1967; Hildebrand et al., 1968; Miyoshi and Goto, 1973). In such animals, the myoinositol content of peripheral nerves is known to be reduced (Stewart et al., 1967; Greene et al., 1974). Greene et al. (1975) later found that with the addition of $1 \%$ myoinositol to the diet of diabetic rats, the reduction in the nerve myoinositol content could be abolished. Moreover, they reported that under these circumstances, the reduction in nerve conduction velocity could be diminished or eliminated. Nerve conduction velocity has also been found to be reduced after feeding galactose to rats (Gabbay and Snider, 1972; Sharma et al., 1976). In this experimental model, the myoinositol content of peripheral nerve is again reduced (Stewart et al., 1967; Gabbay and Snider, 1972; Sharma et al., 1976).

In this study, we have investigated the effect of high dosage dietary myoinositol administration on nerve conduction velocity in rats, and the possible influence of low dosage dietary myoinositol in streptozotocin-induced diabetes.

\section{Methods}

All observations were made on mature male Wistar rats weighing between 410 and $510 \mathrm{~g}$, maintained in plastic metabolic cages on 41B Oxoid diet (Lillico) with water ad libitum. Agematched animals were used in both experiments.

For the high dosage dietary myoinositol experiment, the animals were given $35 \%$ myoinositol (Sigma) by weight added to the 41B Oxoid diet according to the procedure adopted by De Jesus et al. (1974). For the observations on diabetic animals, diabetes was induced by the intraperitoneal injection of a buffered solution of streptozotocin at a dosage of $60 \mathrm{mg} / \mathrm{kg}$ body weight. They usually developed glycosuria of $2 \%$ or more within two days, and regular urine examination revealed glucose concentrations of this level throughout the period studied. The animals given low dose supplementary myoinositol were administered $1 \%$ myoinositol by weight in the diet, according to the regime adopted by Greene et al. (1975). The un- treated 41B Oxoid diet was found to contain $0.023 \%$ inositol. All diets were consumed avidly.

\section{ELECTROPHYSIOLOGICAL RECORDINGS}

Motor nerve conduction velocity was measured in vivo by the method described by Sharma and Thomas (1974). The animals were anaesthetised with ether and placed on an electrically heated pad in a warm room. Skin temperature was measured on the medial aspect of the upper thigh and, in some experiments, intramuscular temperature in the posterior thigh and calf muscles was recorded with a thermistor probe. The right hind limb was held in full extension by strapping. A sterile concentric needle electrode (Disa type K0511) was inserted into the muscles of the first interosseous space of the foot. The sciatic nerve was stimulated through a needle electrode at the sciatic notch and the tibial nerve posterior to the medial malleolus with just supramaximal stimuli delivered from a Devices isolated stimulator at the rate of one per second. The evoked muscle action potentials were suitably amplified and displayed on an oscilloscope. Conduction time between upper and lower stimulation sites was measured from photographs. The distance between the two stimulating points measured on the skin with calipers was taken as the conduction distance and divided by the conduction time to obtain conduction velocity.

\section{BIOCHEMICAL METHODS}

Blood was collected by cardiac puncture at the end of the study and the plasma frozen. Sciatic nerves were removed and frozen in liquid nitrogen.

Preparation of tissue extracts for analysis of free and lipid-inositol Perchloric acid and lipid extracts of weighed frozen tissue samples were prepared as described by Palmano et al. (1977). Portions of the $\mathrm{HClO}_{4}$ supernatant were neutralised with saturated $\mathrm{KHCO}_{3}$ solution, deionised by passage through Amberlite MB3 mixed-bed ion exchange resin (British Drug Houses), and freezedried in preparation for gas-liquid chromatographic (glc) analysis. Prepared lipid extracts were hydrolysed with $6 \mathrm{M}-\mathrm{HC} 1$ to release inositol from lipid and the hydrolysates subjected to glc as also previously described by Palmano et al. (1977).

Preparation of serum Samples of thawed serum $(0.5 \mathrm{ml})$ were deproteinised by the method of Somogyi (1945); the protein-free supernatants were lyophilised and subjected to glc.

Analysis of dietary free inositol Free inositol in the Oxoid diet was measured by the method of Greene et al. (1975).

Gas-liquid chromatography Inositol and free 
sugars in freeze-dried tissue extracts, and hydrolysates were converted into their trimethylsilyl ethers (Sweeley et al., 1963) by reaction with $100 \mu l$ of pyridine/hexamethyldisilazane/trimethylchlorosilane $(5: 2: 1$, by vol.). The tubes were mechanically shaken for $4 \mathrm{~h}$ to ensure complete reaction. Samples were chromatographed on a Pye series 104 gas-liquid chromatograph equipped with hydrogen flame-ionisation detectors. Portions (1$2 \mu \mathrm{l})$ of the reaction mixture were injected with a $10 \mu \mathrm{l}$ microsyringe on to a $180 \mathrm{~cm}$ glass column packed with $3 \%$ SE 30 on Supelcoport (Supelco, Belleforte, PA, USA) and chromatographed with $\mathrm{N}_{2}$ as carrier gas (flow rate $35 \mathrm{ml} / \mathrm{min}$ ) and an oven temperature programme of $180^{\circ} \mathrm{C}$ for $6 \mathrm{~min}$ followed by an increase of $3^{\circ} \mathrm{C} / \mathrm{min}$ to $200^{\circ} \mathrm{C}$. Sugars were identified by comparison of retention times with those of known standards, and quantification was effected by relating peak area of sugar (peak height $X$ width at $\frac{1}{2}$ peak height) to that of an internal standard (methyl $\alpha$-D-mannopyranoside) added to samples before lyophilisation.

\section{Results}

HIGH DOSAGE DIETARY MYOINOSITOL

Motor nerve conduction velocity was measured in the tibial nerve in a group of six rats before and at three, six, and nine weeks after feeding a diet containing $35 \%$ myoinositol. Although the rats remained active and healthy, they progressively lost weight, from an initial mean value of $451 \mathrm{~g}$ to a value of $383 \mathrm{~g}$ at nine weeks. The mean skin temperature on the medial aspect of the upper thigh at the time of the recordings was $35.3^{\circ} \mathrm{C}$, which was identical to the mean intramuscular temperature in the posterior thigh muscles which was also $35.3^{\circ}$. The mean intramuscular temperature in the calf was slightly less at $34.6^{\circ}$. The initial conduction velocity before dosing began was $52.8 \pm 3.7 \mathrm{~m} / \mathrm{s}$ (mean $\pm \mathrm{SD}$ ), and the values after three, six, and nine weeks of dosing were $49.2 \pm 2.6,51.4 \pm 6.0$ and $50.7 \pm 4.0 \mathrm{~m} / \mathrm{s}$ respectively. A two-way analysis of variance performed on the results revealed no significant influence of treatment on conduction velocity $(P>0.25)$, but a significant difference between individual animals $(P<0.05)$.

The detailed results are given in Table 1. A final result was not obtained in one animal, which died during induction of anaesthesia. For the statistical analyses, an estimated value was employed (Snedecor and Cochran, 1971).

Sciatic nerve free and lipid-inositol concentrations after nine weeks were $3.23 \mu \mathrm{mol} / \mathrm{g}$ wet weight and $0.94 \pm 0.48 \mu \mathrm{mol} / \mathrm{g}$ (mean \pm SD) wet
Table 1 Tibial nerve motor conduction velocity (in $\mathrm{m} / \mathrm{s}$ ) before and after administration of $35 \%$ myoinositol in diet

\begin{tabular}{|c|c|c|c|c|}
\hline \multirow[t]{2}{*}{ Animal } & \multirow{2}{*}{$\begin{array}{l}\text { Initial } \\
\text { velocity }\end{array}$} & \multicolumn{3}{|c|}{ After myoinositol } \\
\hline & & Three weeks & Six weeks & Nine weeks \\
\hline $\begin{array}{l}\text { R639 } \\
\text { R640 } \\
\text { R641 } \\
\text { R642 } \\
\text { R643 } \\
\text { R644 }\end{array}$ & $\begin{array}{l}50.0 \\
53.1 \\
46.9 \\
53.4 \\
57.1 \\
55.5\end{array}$ & $\begin{array}{l}47.8 \\
46.4 \\
48.1 \\
48.3 \\
53.3 \\
51.3\end{array}$ & $\begin{array}{l}45.8 \\
48.1 \\
51.3 \\
45.7 \\
57.7 \\
59.5\end{array}$ & $\begin{array}{l}50.0 \\
47.8 \\
- \\
53.8 \\
47.2 \\
57.5\end{array}$ \\
\hline Mean $( \pm S D)$ & $52.8 \pm 3.7$ & $49.2 \pm 2.6$ & $51.4 \pm 6.0$ & $50.7 \pm 4.0$ \\
\hline
\end{tabular}

weight respectively. Although no strict internal controls were performed for this group, comparison of these values with those for the control group of animals on the low dosage dietary myoinositol revealed an increase in sciatic free myoinositol content $(P<0.05)$ with no alteration in sciatic lipid-inositol concentration.

LOW DOSAGE DIETARY MYOINOSITOL IN DIABETIC ANIMALS

Motor conduction velocity was measured in the tibial nerve in three groups of age-matched rats. These comprised six control animals, six diabetic animals, and six diabetic animals with $1 \%$ myoinositol added to the diet. All three groups remained active and healthy. The mean weight for the control animals increased from 455 to $463 \mathrm{~g}$ over the four weeks period of the experiment, whereas it fell from 453 to $290 \mathrm{~g}$ in the diabetic animals, and from 460 to $270 \mathrm{~g}$ in the diabetic/myoinositol animals.

Conduction velocity was measured before the initiation of the experiment and after two and four weeks. The results are given in Table 2 . The mean skin temperature on the medial aspect of the upper thigh at the time of the recordings was $35.5^{\circ}$, $35.1^{\circ}$, and $35.3^{\circ} \mathrm{C}$ in the control, diabetic, and diabetic/myoinositol groups respectively. An analysis of variance of the conduction velocity measurements obtained at four weeks demonstrated that the variation between treatment groups was significantly greater than between animals within the groups $(\mathrm{P}<0.01)$. Conduction velocity in the diabetic animals, which was $44.1 \pm$ $0.93 \mathrm{~m} / \mathrm{s}$, was significantly less than the value in these animals before diabetes was induced when it was $50.4 \pm 2.6 \mathrm{~m} / \mathrm{s}(\mathrm{P}<0.001)$. The addition of $1 \%$ myoinositol to the diet had no significant effect on the reduction $(\mathrm{P}>0.5)$.

Results obtained from glc analysis of tissue extracts from rats killed at completion of studythat is, after four weeks-are given in Table 3. As 
Table 2 Tibial nerve motor conduction velocity (in $\mathrm{m} / \mathrm{s}$ ) in control and diabetic rats, and diabetic rats with $1 \%$ dietary myoinositol

\begin{tabular}{|c|c|c|c|c|}
\hline & \multirow[t]{2}{*}{ Animal } & \multirow{2}{*}{$\begin{array}{l}\text { Initial } \\
\text { velocity }\end{array}$} & \multicolumn{2}{|c|}{ After treatment } \\
\hline & & & Two weeks & Four weeks \\
\hline $\begin{array}{l}\text { Control } \\
\text { Mean ( } \pm \text { SD) }\end{array}$ & $\begin{array}{l}\text { R633 } \\
\text { R634 } \\
\text { R635 } \\
\text { R636 } \\
\text { R637 } \\
\text { R638 }\end{array}$ & $\begin{array}{l}49.5 \\
51.7 \\
46.0 \\
53.5 \\
50.0 \\
51.8 \\
50.4 \pm 2.6\end{array}$ & $\begin{array}{l}47.1 \\
51.7 \\
54.9 \\
49.1 \\
50.5 \\
54.6 \\
51.3 \pm 3.1\end{array}$ & $\begin{array}{l}51.3 \\
55.0 \\
59.8 \\
56.8 \\
57.0 \\
57.7 \\
56.3 \pm 2.9\end{array}$ \\
\hline $\operatorname{Mean}( \pm \mathrm{SD})$ & $\begin{array}{l}\text { R627 } \\
\text { R628 } \\
\text { R629 } \\
\text { R630 } \\
\text { R631 } \\
\text { R632 }\end{array}$ & $\begin{array}{l}50.5 \\
47.4 \\
46.1 \\
48.1 \\
50.0 \\
51.8 \\
49.0 \pm 2.1\end{array}$ & $\begin{array}{l}47.9 \\
47.3 \\
43.8 \\
47.8 \\
45.4 \\
50.9 \\
47.2 \pm 2.4\end{array}$ & $\begin{array}{l}45.6 \\
42.3 \\
41.4 \\
42.4 \\
46.3 \\
46.4 \\
44.1 \pm 2.3\end{array}$ \\
\hline $\begin{array}{l}\text { Diabetic/ } \\
\text { myoinositol }\end{array}$ & $\begin{array}{l}\text { R621 } \\
\text { R622 } \\
\text { R623 } \\
\text { R624 } \\
\text { R625 } \\
\text { R626 }\end{array}$ & $\begin{array}{l}55.4 \\
51.0 \\
51.5 \\
45.7 \\
48.2 \\
55.1 \\
51.2 \pm 3.8\end{array}$ & $\begin{array}{l}44.7 \\
44.2 \\
40.5 \\
45.8 \\
45.7 \\
47.9 \\
44.8 \pm 2.5\end{array}$ & $\begin{array}{l}47.7 \\
44.8 \\
47.6 \\
47.5 \\
46.8 \\
47.6 \\
47.0 \pm 1.1\end{array}$ \\
\hline
\end{tabular}

observed widely elsewhere (Gabbay et al., 1966; Stewart et al., 1966, 1967; Press et al., 1969; Palmano et al., 1977), sciatic sorbitol and fructose concentrations were increased in diabetic rats. No statistically significant differences in sciatic nerve inositol content were demonstrated. No significant variation in sciatic lipid-inositol concentration between control and diabetic groups could be seen. It is interesting, however, that those diabetic rats fed the inositol supplement had a significantly lower nerve lipid-inositol content than the untreated diabetic rats.

Plasma myoinositol concentration in the control and diabetic animals was $0.06 \pm 0.02 \mu \mathrm{mol} / \mathrm{g}$ wet weight. There was a fourfold increase in the diabetic animals with $1 \%$ added dietary myoinositol, in which it was $0.22 \pm 0.17 \mu \mathrm{mol} / \mathrm{g}$ wet weight.

\section{Discussion}

The findings obtained in the present study have failed to confirm a reduction in nerve conduction velocity in rats fed a diet containing $35 \%$ myoinositol, as had been claimed by Clements et al. (1973) and De Jesus et al. (1974). Reznek et al. (1977) found a statistically significant negative correlation between sural nerve conduction velocity and the plasma myoinositol level in patients with chronic renal failure receiving conservative management, although no depression of motor nerve conduction velocity in the peroneal nerve was detected. In view of the present findings, it is possible that the reduced sural nerve conduction velocity was related to some other factor that was positively correlated with hypermyoinositolaemia. The present results confirm the conclusion reached by Reznek et al. (1977) that hypermyoinositolaemia is unlikely to be responsible for the development of uraemic neuropathy.

A significant reduction in conduction velocity in animals with streptozotocin-induced diabetes, as has been documented in numerous previous reports, has been confirmed. In diabetes of up to 12 months in duration, this is not associated with detectable structural changes by the techniques that have so far been employed (Sharma and Thomas, 1974). Claims that a reduction in nerve fibre diameter occurs, affecting the axon to a greater extent than the myelin sheath (Jakobsen, 1976a, b; Jakobsen and Lundbaek, 1976), have not been confirmed (Sharma et al., 1977). Structural changes develop in the peripheral nerve of rats with alloxan-induced diabetes after a period of two years (Powell et al., 1977) which were considered to be unrelated to aging. The alterations in the diabetic animals took the form of a combination of segmental demyelination and remyelination, axonal degeneration and regeneration, intra-axonal deposits including glycogen, and vascular abnormalities.

The finding that in early experimental diabetes conduction velocity is reduced in the absence of detectable structural change raises the possibility that it has a metabolic basis or that any structural change is below the resolution of the techniques so far employed. The report that the reduction could be prevented by the addition of $1 \%$ myoinositol to the diet (Greene et al., 1975) was, therefore, of considerable interest. Unfortunately, the present study has failed to substantiate this observation despite increases of the plasma myoinositol concentration to a comparable extent.

Observations on changes in conduction velocity of modest degree related to experimental manipulations are fraught with a number of difficulties. These may be the explanation for the disparities between some of the present findings and those obtained in previous studies. Firstly, the variation between animals is substantial. This is not just a feature of the in vivo recording method as the variation is just as great when the observations are made in vitro in a recording bath (J. G. R. Jefferys, unpublished observations). The in vivo technique has the merit that it allows serial observations to be made on the same animal. Because of the high interanimal variability, the present results were assessed by an analysis of variance to separate the effects attributable to experimental 
Table 3 Polyol and hexose concentrations in sciatic nerve and plasma of control and diabetic rats $(\mu m o l / g$ wet weight)

\begin{tabular}{|c|c|c|c|c|}
\hline & & Control rats (6) & Diabetic rats (6) & Diabetic/inositol rats (6) \\
\hline $\begin{array}{l}\text { Sciatic nerve } \\
\text { Plasma }\end{array}$ & $\begin{array}{l}\text { Myoinositol } \\
\text { Glucose } \\
\text { Fructose } \\
\text { Sorbitol } \\
\text { Lipid/myoinositol } \\
\text { Myoinositol } \\
\text { Glucose }\end{array}$ & $\begin{array}{l}2.37 \pm 0.64 \\
8.65 \pm 3.83 \\
1.34 \pm 0.54 \\
0.08 \pm 0.05 \\
0.79 \pm 0.28 \\
0.06 \pm 0.02 \\
10.4 \pm 2.2\end{array}$ & $\begin{array}{c}1.97 \pm 0.68 \\
16.30 \pm 4.9^{*} \\
3.66 \pm 1.62^{*} \\
0.54 \pm 0.19 \dagger \\
0.97 \pm 0.25 \\
0.06 \pm 0.02 \\
16.9 \pm 0.16 \dagger\end{array}$ & $\begin{array}{c}2.58 \pm 0.86 \\
19.20 \pm 10.0^{*} \\
2.86 \pm 1.31^{*} \\
1.15 \pm 0.35 \dagger \ddagger \\
0.69 \pm 0.13 \ddagger \\
0.22 \pm 0.17^{*} \ddagger \\
17.5 \pm 3.38^{*}\end{array}$ \\
\hline
\end{tabular}

Values represent mean \pm SD for number of animals studied (in brackets).

*significantly different from control $(P<0.025)$.

tsignificantly different from control $(P<0.001)$.

‡significantly different from untreated diabetic $(P<0.025)$.

manipulation from those due to variation between animals. A second difficulty is that rats do not provide a stationary experimental situation, as growth continues at least during the first nine months of life, although it is substantially more rapid at first. This affects nerve fibre diameter (Dunn, 1912; Sima, 1974) and conduction velocity (Birren and Wall, 1956; Sharma and Thomas, 1974).

There is evidence, from serial observations on individual animals, that rendering rats diabetic slows the normal growth in fibre diameter (Sharma et al., 1977), and would thus be expected to have a similar effect on nerve conduction velocity. It is possible that, in the present series of experiments, in the rats fed $35 \%$ myoinositol the normal growth changes in the peripheral nerves were impaired. Conduction velocity remained substantially unchanged over the nine week period of observation. Normally an increase would have been expected over this period. Although skeletal growth and nerve fibre size were not examined, the possibility that a failure of growth is the explanation is supported by the progressive weight loss exhibited by these animals.

The reduction in motor nerve conduction velocity in the streptozotocin-diabetic rats was not accompanied by a significant reduction in sciatic nerve inositol content, in contrast to the results of Greene et al. (1975). However, it has been observed elsewhere (Palmano et al., 1977) that decrease in inositol content of diabetic nerve tends to be progressive and to become more significant with duration of diabetes. It is likely that no significant reduction in nerve myoinositol was observed in this experiment because the duration of the diabetes was too short.

The influence of dietary inositol on nerve myoinositol concentration (Greene et al., 1975) was shown to some extent in the present study, especially so in the high dosage myoinositol exper- iment where concentration was significantly increased. However, while appearing to modify sciatic myoinositol, dietary myoinositol would seem to have no direct association with conduction velocity; furthermore, no relationship between conduction velocity and sciatic inositol content could be demonstrated. Indeed, the observations concerning conduction velocity and inositol concentration in plasma and peripheral nerve would suggest that something more subtle is involved than alteration in myoinositol levels.

The findings in relation to nerve lipid-inositol are not clear. In the diabetic groups, where conduction velocity is clearly reduced, little change is seen in sciatic lipid-inositol, although diabetic rats fed the inositol supplement had a reduced lipidinositol content when compared with the untreated diabetics. In those normal rats fed a $35 \%$ myoinositol diet, no change in sciatic lipid-inositol or conduction velocity was observed. Hence, overall, no definite conclusions can be reached as to the relationship between nerve lipid-inositol content and conduction velocity.

An important consideration in view of the age and growth associated changes in conduction velocity discussed above, is that Greene et al. (1975) demonstrated a relationship between conduction velocity and nerve myoinositol concentration in young rats (144-155 g). At this age, growth-associated changes might be expected to be more significant, and the pattern of events more susceptible to alteration by adverse factors than in the mature rats $(400-500 \mathrm{~g})$ used in the present study.

We gratefully acknowledge financial support from the Medical Research Council and the National Fund for Research into Crippling Diseases. The streptozotocin was kindly supplied by the Drug Development Branch, Division of Cancer Treatment, National Cancer Institute, USA. 


\section{References}

Birren, J. E., and Wall, P. D. (1956). Age changes in conduction velocity, refractory period, number of fibers, connective tissue space and blood vessels in sciatic nerve of rats. Journal of Comparative Neurology, 104, 1-16.

Clements, R. S., De Jesus, P. V., and Winegrad, A. I. (1973). Raised plasma-myoinositol levels in uraemia and experimental neuropathy. Lancet, 2, 1137-1141.

De Jesus, P. V., Clements, R. S., and Winegrad, A. I. (1974). Hypermyoinositolemic polyneuropathy in rats. A possible mechanism for uremic polyneuropathy. Journal of the Neurological Sciences, 21, 237-249.

Dunn, E. H. (1912). The influence of age, sex, weight and relationship upon the number of medullated nerve fibers and on the size of the largest fibers in the ventral root of the second cervical nerve of the albino rat. Journal of Comparative Neurology, 22, 131-157.

Eichberg, J., and Hauser, G. (1973). The subcellular distribution of polyphosphoinositides in myelinated and unmyelinated rat brain. Biochimica et Biophysica Acta, 326, 210-223.

Eliasson, S. G. (1964). Nerve conduction changes in experimental diabetes. Journal of Clinical Investigation, 43, 2353-2358.

Gabbay, K. H., Merola, L. O., and Field, R. A. (1966). Sorbitol pathway: presence in nerve and cord with substrate accumulation in diabetes. Science, 151, 209-210.

Gabbay, K. H., and Snider, J. J. (1972). Nerve conduction defect in galactose-fed rats. Diabetes, 21, 295-300.

Greene, D. A., De Jesus, P. V., and Winegrad, A. I. (1974). Motor nerve conduction velocity in acute and chronic streptozotocin diabetes. Diabetes, 23, 357.

Greene, D. A., De Jesus, P. V., and Winegrad, A. I. (1975). Effects of insulin and dietary myoinositol on impaired peripheral motor nerve conduction velocity in acute streptozotocin diabetes. Journal of Clinical Investigation, 55, 1326-1336.

Hawthorne, J. N., and Kai, M. (1970). Metabolism of phosphoinositides. In Handbook of Neurochemistry, pp. 491-508. Edited by A. Lajtha. Plenum Press: New York.

Hendrickson, H. S., and Reinertsen, J. L. (1969). Comparison of metal-binding properties of trans-1, 2-cyclohexanediol diphosphate and deacylated phosphoinositides. Biochemistry, 8, 4855-4858.

Hendrickson, H. S., and Reinertsen, J. L. (1971). Phospho-inositide interconversion: a model for control of $\mathrm{Na}^{+}$and $\mathrm{K}+$ permeability in the nerve axon membrane. Biochemical and Biophysical Research Communications. 44, 1258-1264.

Hildebrand, J., Joffroy, A., Graff, G., and Coërs, C. (1968). Neuromuscular changes with alloxan hyperglycemia. Electrophysiological, biochemical and histological study in rats. Archives of Neurology (Chicago). 18, 633-641.
Jakobsen, J. (1976a). Axonal dwindling in early experimental diabetes. I. A study of cross sectioned nerves. Diabetologia, 12, 539-546.

Jakobsen, J. (1976b). Axonal dwindling in early experimental diabetes. II. A study of isolated nerve fibres. Diabetologia, 12, 547-553.

Jakobsen, J., and Lundbaek, K. (1976). Neuropathy in experimental diabetes. An animal model. British Medical Journal, 2, 278-279.

Kai, M., and Hawthorne, J. N. (1969). Physiological significance of polyphosphoinositides in brain. Annals of the New York Academy of Sciences, 165, 761-773.

Miyoshi, T., and Goto, I. (1973). Serial in vivo determinations of nerve conduction velocity in rat tails. Physiological and pathological changes. Electroencephalography and Clinical Neurophysiology, 35, 125-131.

Palmano, K. P., Whiting, P. H., and Hawthorne, J. N. (1977). Free and lipid myo-inositol in tissues from rats with acute and less severe streptozotocin induced diabetes. Biochemical Journal, 167, 229-235.

Powell, H., Knox, D., Lee, S., Charters, A. C., Orloff, M., Garrett, R., and Lampert, P. (1977). Alloxan diabetic neuropathy: electron microscopic studies. Neurology (Minneapolis), 27, 60-66.

Press, R., Margolis, R., and Altszuler, N. (1969). Increased brain fructose production in alloxan diabetes. Federation Proceedings, 28, 828.

Preston, G. M. (1967). Peripheral neuropathy in the alloxan-diabetic rat. Journal of Physiology, 189, 49-50P.

Reznek, R. H., Salway, J. G., and Thomas, P. K. (1977). Plasma-myoinositol concentrations in uraemic neuropathy. Lancet, 1, 675-676.

Sharma, A. K., and Thomas, P. K. (1974). Peripheral nerve structure and function in experimental diabetes. Journal of the Neurological Sciences, 23, 1-15.

Sharma, A. K., Thomas, P. K., and Baker, R. W. R. (1976). Peripheral nerve abnormalities related to galactose administration in rats. Journal of Neurology, Neurosurgery, and Psychiatry, 39, 794-802.

Sharma, A. K., Thomas, P. K. and De Molina, A. F. (1977). Peripheral nerve fiber size in experimental diabetes. Diabetes, 26, 689-692.

Sima, A. (1974). Studies on fibre size in developing sciatic nerve and spinal roots in normal, undernourished and rehabilitated rats. Acta Physiologica Scandinavica, 91, Supplementum 406, 1-55.

Snedecor, E. W., and Cochran, W. E. (1971). Statistical Methods. Sixth edition, p. 317. Iowa State University Press: Ames, Iowa.

Somogyi, M. (1945). Determination of blood sugar. Journal of Biological Chemistry, 160, 69-73.

Stewart, M. A., Sherman, W. R., and Anthony, S. (1966). Free sugars in alloxan diabetic rat nerve. Biochemical and Biophysical Research Communication, 22, 488-491.

Stewart, M. A., Sherman, W. R., Kurien, M. M., Moonsammy, G. I., and Wisgerhof, M. (1967). Polyol accumulations in nervous tissue of rats with 
experimental diabetes and galactosaemia. Journal of Neurochemistry, 14, 1057-1066.

Sweeley, C. C., Bentley, R., Makita, M., and Wells, W. W. (1963). Gas-liquid chromatography of trimethylsilyl derivatives of sugars and related substances. Journal of American Chemical Society, 85, 2497--2507.

White, G. L., and Larrabee, M. G. (1973). Phosphoinositides and other phospholipids in sympathetic ganglia and nerve trunk of rats. Effects of neuronal activity and inositol analogs $[\beta$ - and $\gamma$-hexachlorocyclohexane (lindane)] on (32p)-labelling, synaptic transmission and axonal conduction. Journal of Neurochemistry, 20, 783-798.

Yagihara, Y., Salway, J. G., and Hawthorne, J. N. (1969). Incorporation of 32p in vitro into triphosphoinositide and related lipids of rat superior cervical ganglia and vagus nerves. Journal of Neurochemistry, 16, 1133-1139. 